\title{
Manipulation under Anesthesia for Stiffness after Total Knee Arthroplasty
}

\author{
Ju-Hyung Yoo, MD, Jin-Cheol Oh, MD, Hyun-Cheol Oh, MD, and Sang-Hoon Park, MD \\ Department of Orthopedic Surgery, National Health Insurance Corporation Ilsan Hospital, Goyang, Korea
}

Purpose: This study evaluated the incidence of manipulation under anesthesia (MUA) for stiffness after total knee arthroplasty (TKA) and the degree of joint motion recovery after MUA.

Materials and Methods: A total of 4,449 TKAs (2,973 patients) were performed between March 2000 and August 2014. Cases that underwent MUA for stiffness after TKA were reviewed. TKAs were performed using the conventional procedure in 329 cases and using the minimally invasive procedure in 4,120 cases. The preoperative range of joint motion, timing of manipulation, diagnosis and the range of joint motion before and after MUA were retrospectively investigated.

Results: MUA was carried out in 22 cases (16 patients), resulting in the incidence of $0.5 \%$. The incidence after the conventional procedure was $1.2 \%$ and $0.4 \%$ after the minimally invasive procedure. In the manipulated knees, the preoperative range of motion $(\mathrm{ROM})$ was $102.5^{\circ} \pm 26.7^{\circ}$, and the preoperative diagnosis was osteoarthritis in 19 cases, rheumatoid arthritis in two, and infection sequela in one. MUA was performed $4.7 \pm 3.0$ weeks after TKA. The average ROM was $64.5^{\circ} \pm 13.5^{\circ}$ before manipulation. At an average of $64.3 \pm 41.3$ months after manipulation, the ROM was recovered to $113.4^{\circ} \pm 31.2^{\circ}$, which was an additional $49.9^{\circ}$ improvement in flexion.

Conclusions: The satisfactory recovery of joint movement was achieved when MUA for stiffness was performed relatively early after TKA.

Keywords: Knee, Arthroplasty, Stiffness, Manipulation

\section{Introduction}

One of the major goals of total knee arthroplasty (TKA) is to restore the normal alignment and balance of the knee to ensure long-term survival after joint replacement with pain relief and functional improvement. For this purpose, continuous efforts have been made to improve knee implants, surgical techniques, and postoperative rehabilitation protocols. However, functional problems after TKA that restrict daily living activities can still be

Received May 12, 2015; Revised August 1, 2015;

Accepted August 17, 2015

Correspondence to: Hyun-Cheol Oh, MD

Department of Orthopedic Surgery, National Health Insurance

Corporation Ilsan Hospital, 100 Ilsan-ro, Ilsandong-gu, Goyang 10444, Korea

Tel: +82-31-900-0441, Fax: +82-31-900-0343

E-mail: hyuncoh@hanmail.net

This is an Open Access article distributed under the terms of the Creative Commons Attribution Non-Commercial License (http://creativecommons.org/licenses/by-nc/4.0/) which permits unrestricted non-commercial use, distribution, and reproduction in any medium, provided the original work is properly cited. encountered in some patients. In cases where such problems occur due to the patient's intrinsic characteristics in spite of proper surgical treatment and rehabilitation and the absence of evidence of infection, it is difficult to elucidate the etiology and determine effective treatment approaches ${ }^{1)}$. Stiffness following TKA has been treated with manipulation under anesthesia (MUA) ${ }^{2)}$, arthroscopic release ${ }^{3)}$, open arthrolysis ${ }^{4)}$ or revision $\mathrm{TKA}^{5)}$. Among these, MUA has been considered as the most effective simple primary treatment modality for stiffness that develops within 2-3 months following TKA. Efforts to evaluate the efficacy of arthroscopic release for fibroarthrosis following TKA have been made by domestic researchers ${ }^{6}$; however, the prevalence and efficacy of MUA have never been investigated in Korea. Therefore, we attempted to investigate the prevalence and outcomes of MUA for stiffness in this study.

\section{Materials and Methods}

Of the total 4,449 knees (2,973 patients) that underwent TKA performed by the first author (Yoo) of this study between March 
2000 and August 2014 at our institution, those treated with MUA for stiff knee following TKA were reviewed for this study. During TKA, LCS system (DePuy Inc., Warsaw, IN, USA) was implanted in 181 knees, Maxim prosthesis (Biomet Inc., Warsaw, IN, USA) in 76 knees and NexGen LPS-Flex fixed knee (Zimmer Inc., Warsaw, IN, USA) in 4,192 knees. In the knees with the LCS system, the surgery was performed using a gap technique, whereas in the knees with either the Maxim prosthesis or the NexGen prosthesis, a measured resection technique was used. From March 2000 through mid-July 2004, 329 TKAs were performed using the conventional surgical approach. Thereafter, a minimally invasive surgery (MIS) quad-sparing instrumentation was used in TKA on 4,120 knees: 3,785 of these that underwent MIS TKA after November 2005 received the modular tibial implant ("mini-keel" Nexgen MIS Tibial Component, Zimmer Inc.). The posterior cruciate ligament (PCL) was retained in 128 knees (LCS, 66; Maxim, 50; NexGen, 12) and replaced in 4321 knees (LCS, 115; Maxim, 26; NexGen, 4,180). The patella was preserved in 119 knees (LCS, 76; Maxim, 5; Nexgen, 38) and replaced in 4,330 knees (LCS, 105; Maxim, 71; NexGen, 4,154) (Table 1).

A Hemovac drain was placed in the joint during surgery, which was removed on the 2 nd postoperative day. Continuous passive motion exercises were initiated from the 1st postoperative day. From the 2nd postoperative day, knee flexion off the table was

Table 1. Incidence of Manipulation under Anesthesia (MUA)

\begin{tabular}{|c|c|c|c|c|}
\hline Variable & No. of cases & $\begin{array}{l}\text { No. of } \\
\text { MUA }\end{array}$ & $\begin{array}{c}\text { Incidence } \\
\text { of MUA } \\
(\%)\end{array}$ & $\mathrm{p}$-value \\
\hline Total case & 4,449 & 22 & 0.5 & \\
\hline \multicolumn{5}{|l|}{ Implant } \\
\hline LCS & 181 & 2 & 1.1 & 0.225 \\
\hline Maxim & 76 & 2 & 2.6 & 0.053 \\
\hline NexGen & 4,192 & 18 & 0.4 & $0.035^{\mathrm{a})}$ \\
\hline \multicolumn{5}{|l|}{ Surgical approach } \\
\hline Conventional & 329 & 4 & 1.2 & 0.074 \\
\hline MIS & 4,120 & 18 & 0.4 & \\
\hline \multicolumn{5}{|c|}{$\begin{array}{l}\text { Posterior cruciate } \\
\text { ligament }\end{array}$} \\
\hline Substituting & 4,321 & 19 & 0.4 & $0.024^{\mathrm{a})}$ \\
\hline Retaining & 128 & 3 & 2.3 & \\
\hline \multicolumn{5}{|l|}{ Patella resurface } \\
\hline Yes & 4,330 & 21 & 0.5 & 0.450 \\
\hline No & 119 & 1 & 0.9 & \\
\hline
\end{tabular}

MIS: minimally invasive surgery.

${ }^{a)}$ Statistically significant, $\mathrm{p}<0.05$. started and ambulation was encouraged. From the 3rd postoperative day, joint exercises and physical therapy were instructed by a physical therapist for approximately 2 weeks. At the time of discharge, patients with $<80^{\circ}$ knee flexion or those with progressive stiffness of the knee in spite of $\geq 80^{\circ}$ knee flexion were required to visit the outpatient clinic within 1 to 2 weeks afterwards. In these patients, if the range of flexion was limited to $<80^{\circ}$ in the outpatient visit, MUA was carried out.

Under sufficient muscle relaxation through general or spinal anesthesia, the hip was flexed to $90^{\circ}$. The surgeon placed one hand under the popliteal area so as to maintain the knee joint as the center of the hinge during manipulation. Then, holding the proximal tibia with the other hand, the surgeon gradually applied pressure to elicit flexion of the knee, which was repeatedly performed until signs of breakage of adhesions became palpable or audible in the sufficiently flexed knee. During the process, care was taken not to cause a periprosthetic fracture or a rupture of the extensor mechanism. Subsequently, patient-controlled anesthesia was maintained for two days, and continuous passive motion exercises were started from the day of MUA treatment. From the day after the treatment, aggressive physical therapy was carried out with a therapist until the patient could discharge with sufficient recovery of knee joint function.

The name of diagnosis, preoperative range of motion (ROM) of the knee, postoperative outcomes, postoperative level of stiffness and the timing of manipulation procedure were retrospectively reviewed. Nineteen knees that are available for a minimum 1-year follow-up after manipulation were examined to evaluate the ROM and level of functional recovery. ROM was measured using a goniometer as the angle between two axes that pass through the center of the femur and the center of the lower leg.

Data on the implant type, surgical technique, PCL preservation, and patellar resurfacing were analyzed using the Fisher's exact test to assess relationships with joint stiffness with the level of statistical significance set at $\mathrm{p}<0.05$. All analyses were performed using SPSS ver. 19.0. (IBM Corp., Armonk, NY, USA).

\section{Results}

MUA was required in 22 knees (16 patients, $0.5 \%$ ) of the total 4,449 knees following TKA. The procedure for stiffness was performed in 2/181 (1.1\%) in the knees with the LCS system and in $2 / 76(2.6 \%)$ in the knees with the Maxim complex, and it was least necessary in the knees with the NexGen system $(18 / 4,192$, $0.4 \% ; \mathrm{p}=0.035$ ). TKA using the conventional approach resulted in the necessity of MUA in 4/329 (1.2\%) and TKA using the MIS 
did in $18 / 4,120(0.4 \%, \mathrm{p}=0.074)$. MUA was required in $19 / 4,321$ $(0.4 \%)$ of the PCL replaced knees and in $3 / 128$ (2.3\%) of the PCL preserved knees $(\mathrm{p}=0.024)$; and it was performed in $21 / 4,330$ $(0.5 \%)$ of the patella resurfaced knees and in $1 / 119(0.9 \%)$ of the patella preserved knees $(\mathrm{p}=0.45)$ (Table 1$)$.

The mean age of the patients who underwent MUA was $66.9 \pm 8.6$ years, and there were one male ( 1 knee) and 15 females (21 knees). In them, the preoperative diagnosis was osteoarthritis in 19 knees, rheumatoid arthritis in two knees and complication of infection in one. Their mean preoperative ROM was $102.5^{\circ}$ (range, $65^{\circ}$ to $145^{\circ}$ ), and $<90^{\circ}$ of flexion was observed in 6 knees (five knees with osteoarthritis and one knee with infection sequela) (Table 2). The mean operation time was 93.2 $\pm 16.1 \mathrm{~min}$ utes, and the postoperative hemorrhage volume was $648.2 \pm 333.8$ $\mathrm{mL}$. Intraoperative complication did not occur in any of the patients. The mean postoperative tibial component alignment was $0.1^{\circ} \pm 0.7^{\circ}$ valgus, posterior tibial slope was $3.9^{\circ} \pm 1.1^{\circ}$, and femorotibial angle was $6.0^{\circ} \pm 1.3^{\circ}$ valgus. Varus tibial component alignment $\left(0^{\circ} \pm 3^{\circ}\right)$ was observed in $100 \%$ and valgus femorotibial angle $\left(6^{\circ} \pm 3^{\circ}\right)$ was noted in $95.5 \%$ (Table 3). MUA was carried out during initial hospitalization before discharge in 11 knees and during re-hospitalization in 11 knees, which was at $4.7 \pm 3.0$ weeks (range, 1.4 to 13.9 weeks) after TKA. The mean ROM before manipulation was $64.5^{\circ} \pm 13.5^{\circ}$ (range, $30^{\circ}$ to $80^{\circ}$ ). Nineteen knees were available for $\geq 1$-year follow-up, and the mean follow-up pe-

Table 2. Demographics of Patients with Manipulation under Anesthesia

\begin{tabular}{lc}
\hline \multicolumn{1}{c}{ Characteristic } & Value \\
\hline No. of cases (patients) & $22(16)$ \\
Gender & 1 \\
Male & 21 \\
Female & $66.9 \pm 8.6$ \\
Age $(\mathrm{yr})$ & $27.4 \pm 4.0$ \\
Body mass index $\left(\mathrm{kg} / \mathrm{m}^{2}\right)$ & \\
Preop diagnosis $($ case $)$ & 19 \\
OA & 2 \\
RA & 1 \\
etc. (septic knee) & $102.5 \pm 26.7$ \\
Preop ROM $\left({ }^{\circ}\right)$ & 6 \\
ROM $<90($ cases $)$ & $55.0 \pm 15.1$ \\
Preop HSS score & $4.9 \pm 4.3$ varus \\
Preop femorotibial angle $\left({ }^{\circ}\right)$ &
\end{tabular}

Values are presented as mean \pm standard deviation or number. OA: osteoarthritis, RA: rheumatoid arthritis, Preop: preoperative, ROM: range of motion, HSS: Hospital for Special Surgery. riod was $64.3 \pm 41.3$ months (range, 15 to 158 months). At the last follow-up, including the one knee that had $0^{\circ}$ extension ankylosis of the knee, the mean ROM was recovered to $113.4^{\circ} \pm 31.2^{\circ}$ (range, $0^{\circ}$ to $145^{\circ}$ ), indicating a mean of $48.9^{\circ}$ improvement in flexion. At the last follow-up, the Knee Society knee score was $88.3 \pm 13.1$ points (range, 45 to 100 points), Knee Society functional score was $65.8 \pm 18.9$ points (range, 30 to 100 points) and the Hospital for Special Surgery score was $80.1 \pm 10.9$ points (range, 57 to 99 points) (Tables 4 and 5).

In the 60-year-old female patient who exhibited $0^{\circ}$ extension ankylosis at the last follow-up, the indication for TKA was rheumatoid arthritis. The postoperative ROM was restricted to $75^{\circ}$ in the patient; thus, MUA was carried out at 8 weeks after TKA. However, limited ROM recurred after the procedure, which eventually resulted in $0^{\circ}$ extension ankylosis at 1 year after surgery (Fig. 1).

\section{Discussion}

The minimum ROM of the knee for resuming normal daily living activities after TKA is $90^{\circ}$ of flexion, and $\geq 110^{\circ}$ of flexion is desirable for advanced level of activities ${ }^{7,8)}$. Joint stiffness can be defined as limited ROM that restricts activities of daily living. In the past, a knee with $<45^{\circ}$ of $\mathrm{ROM}$ and $\geq 20^{\circ}$ of flexion contracture was considered stiff ${ }^{9}$. However, the growing expectation of the patients and surgeons has raised the bar on the definition of stiffness: $\angle 70^{\circ}$ of ROM according to Christensen et al. ${ }^{10)}$ and $<75^{\circ}$ of ROM and $\geq 15^{\circ}$ of flexion contracture according to Kim et al. ${ }^{11}$. Stiffness following TKA can be associated with preoperative/ intraoperative/postoperative patient characteristics. Regarding the preoperative factors, adhesions of the extensor mechanism and joint capsule are often observed during TKA in patients with

Table 3. Postoperative Data of Patients with Manipulation under Anesthesia

\begin{tabular}{lc}
\hline \multicolumn{1}{c}{ Characteristic } & Value \\
\hline Surgical data & \\
Operation time $(\mathrm{min})$ & $93.2 \pm 16.1$ \\
Blood loss $(\mathrm{mL})$ & $648.2 \pm 333.8$ \\
Radiological data & $0.1 \pm 0.7$ valgus \\
Tibial component alignment angle $\left(^{\circ}\right)$ & $3.9 \pm 1.1$ \\
Tibial component posterior inclination $\left(^{\circ}\right)$ & $6.0 \pm 1.3$ valgus \\
Femorotibial angle $\left(^{\circ}\right)$ & 100 \\
Tibial component alignment angle in $0^{\circ} \pm 3^{\circ}(\%)$ & 95.5 \\
Femorotibial angle in $6^{\circ} \pm 3^{\circ}(\%)$ &
\end{tabular}

Values are presented as mean \pm standard deviation or percentage. SD: standard deviation. 
Table 4. Patients with Manipulation under Anesthesia (MUA)

\begin{tabular}{|c|c|c|c|c|c|c|c|c|c|c|c|c|}
\hline No. & Site & $\begin{array}{l}\text { Age } \\
(\mathrm{yr})\end{array}$ & Sex & $\begin{array}{l}\text { Preop } \\
\text { Dx }\end{array}$ & $\begin{array}{c}\text { Preop } \\
\operatorname{ROM}\left({ }^{\circ}\right)\end{array}$ & Implant & $\begin{array}{c}\text { Patella } \\
\text { resurfacing }\end{array}$ & PCL & $\begin{array}{c}\text { ROM before } \\
\text { MUA }\left(^{\circ}\right)\end{array}$ & $\begin{array}{l}\text { Interval } \\
(\mathrm{wk})^{\mathrm{a})}\end{array}$ & $\begin{array}{l}\text { Last F/U } \\
(\mathrm{mo})\end{array}$ & $\begin{array}{c}\text { ROM at last } \mathrm{F} / \mathrm{U} \\
\left({ }^{\circ}\right)\end{array}$ \\
\hline 1 & $\mathrm{R}$ & 61 & $\mathrm{~F}$ & $\mathrm{OA}$ & 90 & LCS & No & PS & $55(20-75)$ & 13.9 & 158 & $75(10-85)$ \\
\hline 2 & $\mathrm{R}$ & 71 & $\mathrm{~F}$ & IS & 115 & Maxim & Yes & $\mathrm{CR}$ & $70(0-70)$ & 2.1 & 78 & $120(10-130)$ \\
\hline \multirow[t]{2}{*}{3} & $\mathrm{~L}$ & 60 & $\mathrm{~F}$ & RA & 70 & LCS & Yes & $\mathrm{CR}$ & $75(0-75)$ & 8.1 & 113 & 0 \\
\hline & $\mathrm{R}$ & & & & 70 & Maxim & Yes & CR & $80(0-80)$ & 5.4 & 113 & $100(0-100)$ \\
\hline 4 & $\mathrm{~L}$ & 63 & $\mathrm{~F}$ & $\mathrm{OA}$ & 115 & NexGen & Yes & PS & $70(0-70)$ & 8 & 126 & $140(0-140)$ \\
\hline \multirow[t]{2}{*}{5} & $\mathrm{~L}$ & 86 & $\mathrm{~F}$ & $\mathrm{OA}$ & 100 & NexGen & Yes & PS & $60(0-60)$ & 1.4 & 22 & $110(0-110)$ \\
\hline & $\mathrm{R}$ & & & & 100 & NexGen & Yes & PS & $70(0-70)$ & 4.3 & 22 & $110(0-110)$ \\
\hline \multirow[t]{2}{*}{6} & $\mathrm{~L}$ & 74 & $\mathrm{~F}$ & $\mathrm{OA}$ & 115 & NexGen & Yes & PS & $70(0-70)$ & 2.1 & 66 & $130(0-130)$ \\
\hline & $\mathrm{R}$ & & & & 135 & NexGen & Yes & PS & $70(0-70)$ & 2.1 & 66 & $125(0-125)$ \\
\hline \multirow[t]{2}{*}{7} & $\mathrm{~L}$ & 59 & $\mathrm{~F}$ & $\mathrm{OA}$ & 80 & NexGen & Yes & PS & $70(15-85)$ & 8.1 & 72 & $125(0-125)$ \\
\hline & $\mathrm{R}$ & & & & 90 & NexGen & Yes & PS & 75 (20-95) & 8.1 & 72 & $120(0-120)$ \\
\hline 8 & $\mathrm{~L}$ & 65 & F & $\mathrm{OA}$ & 65 & NexGen & Yes & PS & $75(15-90)$ & 3.9 & 93 & $105(5-110)$ \\
\hline \multirow[t]{2}{*}{9} & $\mathrm{~L}$ & 70 & $\mathrm{~F}$ & $\mathrm{OA}$ & 115 & NexGen & Yes & PS & $80(10-90)$ & 4.1 & $3^{\text {b) }}$ & $125(5-130)$ \\
\hline & $\mathrm{R}$ & & & & 90 & NexGen & Yes & PS & $35(15-50)$ & 4.1 & $3^{\mathrm{b})}$ & $70(20-90)$ \\
\hline 10 & $\mathrm{R}$ & 74 & F & $\mathrm{OA}$ & 140 & NexGen & Yes & PS & $60(0-60)$ & 2.4 & 60 & $135(0-135)$ \\
\hline 11 & $\mathrm{R}$ & 71 & $\mathrm{~F}$ & $\mathrm{OA}$ & 65 & NexGen & Yes & PS & $70(5-75)$ & 7.4 & $2^{\mathrm{b})}$ & 95 (0-95) \\
\hline 12 & $\mathrm{~L}$ & 65 & M & $\mathrm{OA}$ & 145 & NexGen & Yes & PS & $70(0-70)$ & 3.1 & 67 & $135(0-135)$ \\
\hline 13 & $\mathrm{R}$ & 71 & $\mathrm{~F}$ & OA & 70 & NexGen & Yes & PS & $30(0-30)$ & 1.9 & 23 & $125(0-125)$ \\
\hline \multirow[t]{2}{*}{14} & $\mathrm{~L}$ & 57 & $\mathrm{~F}$ & $\mathrm{OA}$ & 145 & NexGen & Yes & PS & $75(0-75)$ & 2.9 & 18 & $145(0-145)$ \\
\hline & $\mathrm{R}$ & & & & 145 & NexGen & Yes & PS & $40(0-40)$ & 2.9 & 18 & $135(0-135)$ \\
\hline 15 & $\mathrm{R}$ & 53 & $\mathrm{~F}$ & $\mathrm{OA}$ & 90 & NexGen & Yes & PS & $60(0-60)$ & 3.6 & 20 & $110(0-110)$ \\
\hline 16 & $\mathrm{R}$ & 66 & $\mathrm{~F}$ & $\mathrm{OA}$ & 105 & NexGen & Yes & PS & $60(10-70)$ & 4.1 & 15 & $110(10-120)$ \\
\hline
\end{tabular}

Values are presented as mean (range).

Preop: preoperative, Dx: diagnosis, ROM: range of motion, PCL: posterior cruciate ligament, F/U: follow-up, R: right, OA: osteoarthritis, PS: posterior stabilized, IS: infection sequelae, CR: cruciate retaining, L: left, RA: rheumatoid arthritis.

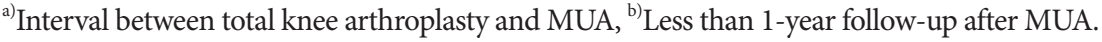

Table 5. Results of Manipulation under Anesthesia (MUA)

\begin{tabular}{lc}
\hline \multicolumn{1}{c}{ Variable } & Mean \pm SD \\
\hline ROM before MUA $\left(^{\circ}\right)$ & $64.5 \pm 13.5$ \\
MUA time after surgery (wk) & $4.7 \pm 2.9$ \\
Follow-up period after MUA (mo) & $49.5 \pm 43.1$ \\
At final follow-up & \\
ROM $\left(^{\circ}\right)$ & $109.3 \pm 30.3$ \\
Pain score & $84.0 \pm 14.4$ \\
Functional score & $61.1 \pm 17.6$ \\
Knee score & $78.4 \pm 10.5$ \\
\hline
\end{tabular}

SD: standard deviation, ROM: range of motion.

functional impairment of an unknown cause, chronic inflammation, infection and previous surgery, which may eventually result in the development of stiffness in spite of adequate release during
TKA due to the already decreased elasticity ${ }^{12,13)}$. Intraoperative factors associated with stiff knees include flexion-extension gap imbalance, soft tissue imbalance, improper knee alignment, inadequate resection of the femur/tibia, incorrect implant position, insufficient restoration of the joint line, implant size mismatch, inaccurate anterior tibial slope, imperfect removal of the posterior femoral osteophytes, patellofemoral joint overstuffing and excessive strain on the PCL in the PCL retained knee ${ }^{10,14)}$. Possible postoperative causes include insufficient pain management after TKA, patient's low motivation and compliance, depression, intra-articular bleeding due to antithrombotic therapy, infection, improper and insufficient physical therapy ${ }^{15)}$, heterotopic ossification ${ }^{16)}$, complex regional pain syndrome ${ }^{17)}$ and arthrofibrosis ${ }^{17}$. Arthrofibrosis is a specific condition characterized by formation of excessive scar tissue in response to intraoperative injury. In worst cases, stiffness can be combined with arthrofibrosis, increased scar tis- 

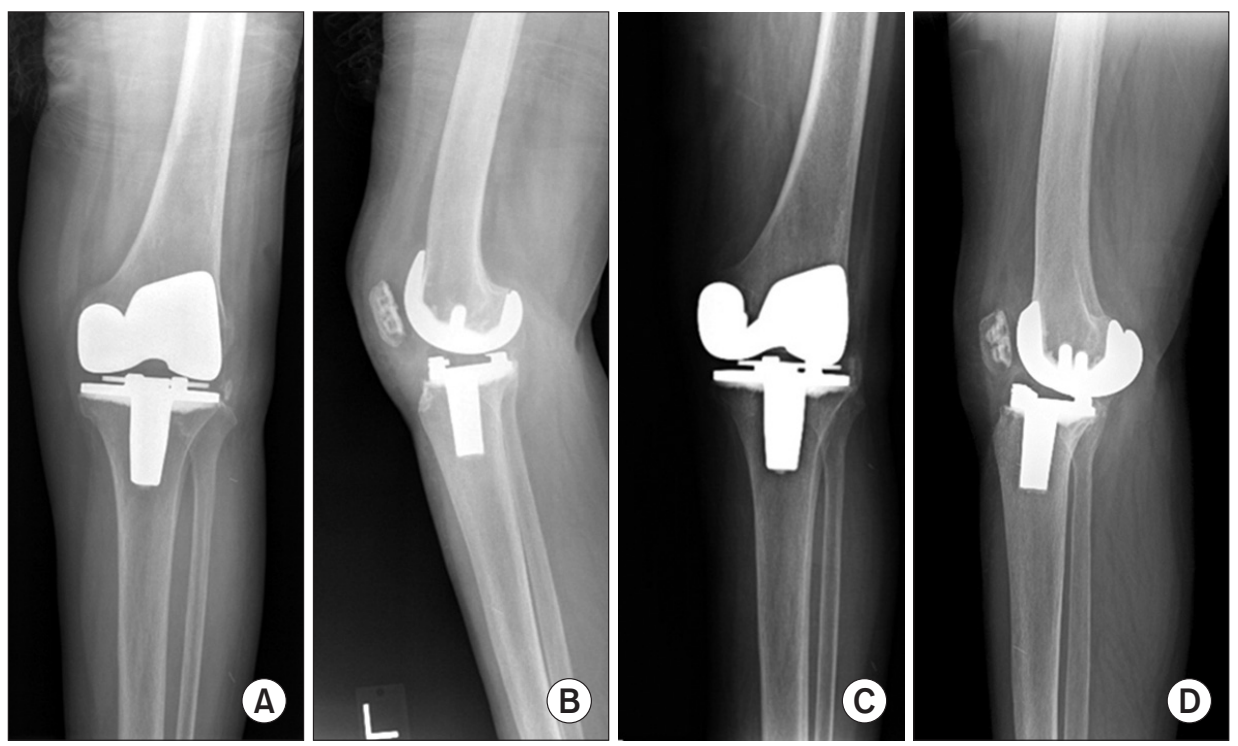

Fig. 1. Radiographs of a 60-year-old woman with rheumatoid arthritis. (A, B) Images obtained 2 months after manipulation show a good alignment. However, stiffness that restricted the range of motion to $70^{\circ}$ recurred. (C, D) Radiographs at 9 years and 7 months after surgery showing $0^{\circ}$ extension ankylosis of the knee joint.

sue formation, formation of fibrous bands of scar tissue between the femur and the quadriceps, loss of suprapatellar bursa, shortening of the lateral expansion of the quadriceps, shortening of the rectus femoris muscle and restricted patellofemoral joint motion. Postoperative knee joint stiffness is difficult to predict, and, albeit unestablished, some studies attributed it to genetic inheritance in some patients.

MUA has been known as the most effective first-line treatment for knees presenting with $<90^{\circ}$ of flexion when aggressive postoperative efforts for restoration of joint motion are ineffective and specific factors, such as infection, are not responsible for the stiffness. It can be efficacious for restricted flexion, but not for flexion contracture. Fibrous tissue that forms after surgery needs 6 months of period for loss of cells and blood vessels until maturity. However, the extent of stiffness is more related to the amount and location of the fibrous tissue than to the level of maturity. Joint stiffness tends to worsen and become persistent in 6 weeks; therefore, manipulation for stiffness should be performed before the maturity of fibrous tissue so as to prevent complications and restore joint mobility ${ }^{18}$. It has been recommended to carry out MUA once joint stiffness is observed even within 2-3 weeks after surgery in some studies ${ }^{19,20)}$ and within 2 weeks to 3 months after surgery in other studies ${ }^{21,22)}$. Esler et al. ${ }^{22)}$ suggested knees with $<80^{\circ}$ of flexion be treated with manipulation irrespective of the time after surgery, preferably within 4 months after surgery. In the current study, knees with $<80^{\circ}$ of flexion were manipulated at a mean of $4.7 \pm 2.9$ weeks (range, 1.4 to 13.9 weeks) after surgery.

The incidence of MUA was $4.6 \%$ in 800 knees in the study of Rubinstein and DeHaan ${ }^{23)}$ and $4.3 \%$ in 3,244 knees in the study of Bawa et al. ${ }^{24)}$. In comparison, the value was relatively low with
$0.5 \%$ in the current study.

Fox and Poss ${ }^{20)}$ reported that MUA did not make any difference in the one-year outcome of TKA, and Esler et al. ${ }^{22}$ also described that patients without MUA also achieved sustained gains in flexion for one year after surgery. However, most studies showed that manipulated knees obtained greater range of flexion. Yercan et al. ${ }^{13)}$ observed a mean of $47^{\circ}$ of increase in flexion after 46 TKAs within 31 months. Mohammed et al. ${ }^{2)}$ found $31.6^{\circ}$ of improvement in 21 knees at 6 months after surgery, and Esler et al. ${ }^{22}$ reported 47 knees obtained a mean of $33^{\circ}$ of improvement at one year after surgery. In our study, including the one knee that had $0^{\circ}$ extension ankylosis, there was a mean of $49.9^{\circ}$ of gain in flexion to $113.4^{\circ} \pm 31.2^{\circ}$ at $64.3 \pm 41.3$ months after MUA.

In the current study, the incidence of MUA was $0.5 \%$ and the mean increase in flexion after TKA was $44.8^{\circ}$, indicating relatively good outcomes. We attribute these relatively favorable results to 1) early diagnosis of stiffness during the 2 weeks of hospitalization, 2) aggressive physical therapy performed under the supervision of the surgeon, and 3) prompt decision on the need for manipulation, which was carried out when normal range of flexion deemed unattainable with physical therapy alone during hospitalization and when early outpatient follow-up assessments indicated elevated risk of progression to stiffness in spite of some improvement in flexion.

Sherry et al. ${ }^{25)}$ reported that MIS total hip replacement was effective in reducing joint stiffness and McAllister and Stepanian ${ }^{26)}$ showed that the incidence of MUA was lower after MIS TKA than TKA with the conventional method required (2\% vs. $14 \%$ ). In the current study, we also observed MUA was required more in patients with the conventional TKA (1.2\%) than in those with 
MIS TKA (0.4\%) although no statistically significant difference was noted between the groups. In our opinion, considering that intraoperative soft tissue injury may result in keloid formation and fibrosis during the healing process, our efforts to minimize injury to soft tissue contributed to the reduced incidence of postoperative stiffness.

\section{Conclusions}

Early MUA was effective in restoring satisfactory ROM in stiff knees following TKA.

\section{Conflict of Interest}

No potential conflict of interest relevant to this article was reported.

\section{References}

1. Seyler TM, Marker DR, Bhave A, Plate JF, Marulanda GA, Bonutti PM, Delanois RE, Mont MA. Functional problems and arthrofibrosis following total knee arthroplasty. J Bone Joint Surg Am. 2007;89 Suppl 3:59-69.

2. Mohammed R, Syed S, Ahmed N. Manipulation under anaesthesia for stiffness following knee arthroplasty. Ann R Coll Surg Engl. 2009;91:220-3.

3. Scranton PE Jr. Management of knee pain and stiffness after total knee arthroplasty. J Arthroplasty. 2001;16:428-35.

4. Hutchinson JR, Parish EN, Cross MJ. Results of open arthrolysis for the treatment of stiffness after total knee replacement. J Bone Joint Surg Br. 2005;87:1357-60.

5. Keeney JA, Clohisy JC, Curry M, Maloney WJ. Revision total knee arthroplasty for restricted motion. Clin Orthop Relat Res. 2005;440:135-40.

6. Bae DK, Lee HK, Cho JH. Arthroscopy of symptomatic total knee replacements. Arthroscopy. 1995;11:664-71.

7. Rowe PJ, Myles CM, Walker C, Nutton R. Knee joint kinematics in gait and other functional activities measured using flexible electrogoniometry: how much knee motion is sufficient for normal daily life? Gait Posture. 2000;12:143-55.

8. Laubenthal KN, Smidt GL, Kettelkamp DB. A quantitative analysis of knee motion during activities of daily living. Phys Ther. 1972;52:34-43.

9. Nicholls DW, Dorr LD. Revision surgery for stiff total knee arthroplasty. J Arthroplasty. 1990;5 Suppl:S73-7.

10. Christensen CP, Crawford JJ, Olin MD, Vail TP. Revision of the stiff total knee arthroplasty. J Arthroplasty. 2002;17:40915.

11. Kim J, Nelson CL, Lotke PA. Stiffness after total knee arthroplasty. Prevalence of the complication and outcomes of revision. J Bone Joint Surg Am. 2004;86:1479-84.

12. Scuderi GR. The stiff total knee arthroplasty: causality and solution. J Arthroplasty. 2005;20(4 Suppl 2):23-6.

13. Yercan HS, Sugun TS, Bussiere C, Ait Si Selmi T, Davies A, Neyret P. Stiffness after total knee arthroplasty: prevalence, management and outcomes. Knee. 2006;13:111-7.

14. Laskin RS, Beksac B. Stiffness after total knee arthroplasty. J Arthroplasty. 2004;19(4 Suppl 1):41-6.

15. Fisher DA, Dierckman B, Watts MR, Davis K. Looks good but feels bad: factors that contribute to poor results after total knee arthroplasty. J Arthroplasty. 2007;22(6 Suppl 2):3942.

16. Furia JP, Pellegrini VD Jr. Heterotopic ossification following primary total knee arthroplasty. J Arthroplasty. 1995;10:413-9.

17. Harden RN, Bruehl S, Stanos S, Brander V, Chung OY, Saltz S, Adams A, Stulberg SD. Prospective examination of painrelated and psychological predictors of CRPS-like phenomena following total knee arthroplasty: a preliminary study. Pain. 2003;106:393-400.

18. Mariani PP, Santori N, Rovere P, Della Rocca C, Adriani E. Histological and structural study of the adhesive tissue in knee fibroarthrosis: a clinical-pathological correlation. Arthroscopy. 1997;13:313-8.

19. Shoji H, Yoshino S, Komagamine M. Improved range of motion with the Y/S total knee arthroplasty system. Clin Orthop Relat Res. 1987;(218):150-63.

20. Fox JL, Poss R. The role of manipulation following total knee replacement. J Bone Joint Surg Am. 1981;63:357-62.

21. Daluga D, Lombardi AV Jr, Mallory TH, Vaughn BK. Knee manipulation following total knee arthroplasty. Analysis of prognostic variables. J Arthroplasty. 1991;6:119-28.

22. Esler CN, Lock K, Harper WM, Gregg PJ. Manipulation of total knee replacements. Is the flexion gained retained? J Bone Joint Surg Br. 1999;81:27-9.

23. Rubinstein RA Jr, DeHaan A. The incidence and results of manipulation after primary total knee arthroplasty. Knee. 2010;17:29-32.

24. Bawa HS, Wera GD, Kraay MJ, Marcus RE, Goldberg VM. Predictors of range of motion in patients undergoing manipulation after TKA. Clin Orthop Relat Res. 2013;471:25863.

25. Sherry E, Egan M, Warnke PH, Henderson A, Eslick GD. 
Knee Surg Relat Res, Vol. 27, No. 4, Dec. 2015239

Minimal invasive surgery for hip replacement: a new technique using the NILNAV hip system. ANZ J Surg. 2003; 73:157-61.
26. McAllister CM, Stepanian JD. The impact of minimally invasive surgical techniques on early range of motion after primary total knee arthroplasty. J Arthroplasty. 2008;23:10-8. 